\title{
Scaffolding Collaborative Learning in Pairs within a Technology-Enhanced Learning Environment
}

\author{
Per B. Bergamin, Egon Werlen, and Yves E. Bochud
}

\begin{abstract}
Previous research shows that scaffolding is an effective method to foster learning in technology-enhanced learning environments demanding self-regulation. This study considers the option of using a scaffold in an online learning environment working with a partner to solve a multiple-choice assessment. A scaffolding sequence was designed in which subjects worked in pairs. Then the collaborative and individual learning performances were measured and compared. Using the cognitive load theory(CLT), variables were defined to explain effects on performance. Participants in the experiment included 41 university students. Findings reveal that learners learning in the collaborative learning scenario performed better than within the individual learning scenario. Results show that three interrelated variables, mental effort, task difficulty and motivation affected performance.
\end{abstract}

Index Terms-Technology enhanced learning, collaborative learning, scaffolding, cognitive load.

\section{INTRODUCTION}

Learning complex science topics within technology-enhanced environments requires students to regulate their own learning process [1]. In self-regulated learning, students must make decisions about what and how to learn, how much time to spend, and how to access other instructional material and to control understanding of the learning content. According to cognitive Load Theory (CLT), collaborative learning opposed to individual learning creates additional learning tasks that increase the load in the working memory (WM), thus affecting learning efficiency. Research in the last decade shows inconsistent data with positive as well as negative effects [2]. However, the use of scaffolds within technology-enhanced environments improves self-regulation in learning [3]. In our study, we investigate the relationship between cognitive load and learning performance, using Multiple-Choice-Assessments in technology-enhanced environments with students working in pairs or alone.

\section{LITERATURE REVIEW}

\section{A. Collaborative Learning Research}

Dillenbourg defines collaborative learning as a situation in which two or more persons learn together [4]. It is therefore necessary to take the learner, task and group characteristics

Manuscriptreceived April 9, 2015; revised September 22, 2015.

Per B. Bergamin and Egon Werlen are with the Swiss Distance University of Applied Sciences, Überlandstrasse 12, 3900 Brig, Switzerland (e-mail: per.bergamin@ffhs.ch, egon.werlen@ffhs.ch).

Yves E. Bochud is with the University of Berne, Institute of Psychology, Fabrikstrasse 8, 3012 Bern, Switzerland (e-mail: yves.bochud@gmail.com). into consideration. It is often assumed in collaborative learning concepts that the construction of knowledge is triggered by dialogue. It has been found that learning processes are positively affected by collaborative learning activities such as developing, proposing and extending arguments, negotiating meaning, verbalizing explanations, and justifying reflections [2]. But not all studies have shown positive effects [5]. However, positive results were often found in learning environments that were technology enhanced and closely linked to structured learning processes (e.g. scaffolding). In such environments learners receive clarification about the required knowledge, as well as how and with whom they should collaborate.

\section{B. Scaffolding in Online Learning Environments}

The term of scaffolding was introduced by Wood [6] and corresponds conceptually to Vygotskys' Zone of Proximal Development and is a structured pedagogical tool that aims to support a student's learning of difficult material. In reviewing the last decade of research, Van de Pol, Volman and Beishuizen suggest six instructional practices that are typically used in scaffolding: giving feed-back, hinting, instructing, explaining, modeling and questioning [7].

When conceptualizing scaffolds within these practices by using technology-enhanced learning environments, some specific characteristics need consideration. In this context Azevedo, Cromley, and Seibert define scaffolds as "tools, strategies, and guides that can support students in regulating their understanding of complex topics when using hypermedia" [8].Van der Pol et al. reviewed several different studies on the effectiveness of scaffolding, and concluded that scaffolding is effective [7]. Some authors also distinguish between fixed and adaptive scaffolding. Fixed scaffolding is static, without changing the components while adaptive is dynamic, implying an adaptation of the components to meet students' needs while learning. In a meta-analysis of the effectiveness of procedures influencing learning performance with dynamic assessment scaffolding, Swanson and Lussier found a medium effect size $d=0.48$ (coaching $d=0.21$; general strategies $d=0.65$ ) [9]. But there are also studies showing positive effects for the fixed scaffolds [10].

\section{Designing COllaborative ScAFFOLDS}

\section{A. Dimensions of the Design}

In our viewpoint, based on the research mentioned above, there are three dimensions suitable for the conceptualization of scaffolds within online environments: interactions, purposes and sources [11].The interactions within scaffolds can be regarded as static or dynamic related to the students' 
learning activities. Static scaffolding consists typically of a set of stable instructions being given without any negotiation between students [11] or teachers, or any human-computer interaction. In contrast, dynamic scaffolds rely on an analysis of the learners' behavior [12] to assess progress and provide feedback within the learning process. Hannafin et al. present a classification of four scaffolding types: 1) procedural scaffolding providing operational steps, 2) conceptual scaffolding which guides learners, 3) strategic scaffolding that suggests alternative routes, and 4) metacognitive scaffolding [1]. The latter supports reflections on learning goals, monitoring learning processes and assessing actual progress. In several studies procedural scaffolding was shown to be efficient [13]. In the context of learning collaboratively these scaffolds are designed to guide thinking and to answer given questions before discussing with others[14].The purpose of procedural scaffold is to engage students in two specific learning activities. The first of these is task-management (e.g. organizing the collaboration and time planning of activities etc.) which aims to reduce the task-complexity related to the learning process. The second activity concerns reconstruction of knowledge, by students engaging with each other to negotiate different perspectives.

Also three sources as third scaffolding dimension are often deployed [11]. These are teachers, peers, and the technology. In this context the combination of peers and technology-enhanced environments seems to be a promising way to improve collaboration. When students work collaboratively they can benefit from each other by explaining their ideas to each other, by verbalizing their individual understanding and realizing that there are other ideas and concepts. Such interaction helps to develop perspectives of the learning topic or concepts. Peer-feedback plays a crucial part and can be regarded as a collaborative learning form, leading to benefits for both the addressee and the assessor [15]. However, peer feedback can vary, and can be correct, incorrect or misleading.

\section{B. Design for Scaffolding Multiple-Choice Exercises}

A crucial element for collaborative learning is the task and its implementation in the learning environment. Metacognitive aspects of scaffolding assist students on how to manage the learning process and procedural scaffolding on how to use tools or functions of the learning environment. In this study, we investigated Multiple-Choice Questions (MCQ) on a complex learning topic, assuming that assessing procedures with MCQ is an option to learn more in depth about peer scenarios [16]. If we look to types of the collaborative communication sequences, the justification is an efficient possibility. For instance Wang [17] tested a MCQ-system that included comments on the questions, and it was possible for other students to read these comments and give recommendations. He found that students commenting and recommending questions enhanced their self-regulated learning abilities and performance.

Based on the above-mentioned findings, and based on learning platform (Moodle, Version 1.9) we developed a scaffold for learning in pairs with eight process steps:

1) Instruction with an exercise on learning and knowing the collaborative working process
2) Creating learning dyads

3) Planning time-management of common learning activities

4) Choosing one of two learning topics (one for each student)

5) Proposing answers (MCQ) and argumentation

6) Reviewing answers and arguments of the peer

7) Solving the multiple-choice quiz

8) Monitoring time and result(s).

For programming, we used the Moodle-Plugin 'conditional activities' from the Centre of Innovation for the Information Society (CICEI) at the University of Las Palmas de Gran Canaria (ULPGC, Spain) and added some additional functions with in-house programming. Fig. 1 (see next page) exemplifies some of the main screens that appear when student dyads learning together (step 3 to 8 ).

\section{Cognitive LoAd, Motivation AND Collaborative LEARNING}

Studying learning collaboration means not only observing the characteristics of the collaboration, but also paying attention to the structures constituting the cognitive architecture of the individuals working together. Cognitive Load Theory (CLT) situates this architecture in the context of the effectiveness of instruction, assuming that the human cognitive architecture consists of an unlimited long-term memory (LTM) which interacts with the working memory (WM) that is limited in capacity and duration [18]. Several researchers have argued that one way to positively affect this limitation of individual learners is by forming groups and initiating collaboration. In this view, learners are imagined to bean information processing system in which group building leads to more available cognitive processing capacity than in individual learning situations [5]. Current theories assume a complex relationship between different factors of cognitive load. Sweller proposes the element of interactivity in the form of task difficulty causes either a cognitive load that is intrinsic (imposed by the task) or an extraneous load (imposed by activities that do not contribute directly to learning, e.g. organization of learning resources etc.) [19]. However, collaborative learning has different characteristics than individuallearning. Ontheonehand, itcanbearguedthatincollab orative learning between individuals, a larger reservoir of cognitive capacity is created and if task difficulty is stable, there is more WM capacity available compared to individual learning. On the other hand, it requires inter-individual communication and information coordination between the individuals, which leads to so-called transaction costs producing extraneous load affecting learning performance [20]. Furthermore, there is also a relationship between extraneous and intrinsic load because of enhanced learning goals, such as collaboration, that can also be allocated in a growth of task difficulty, which leads to an increase of intrinsic load. This means that extraneous and intrinsic load should be managed properly by reducing the elements that impose task. Following this, our study actually poses two research questions: First, does collaborative learning within the developed scaffold lead to better learning performance than the individual learning scenario? Second, how do the 
factors of additional mental effort and task difficulty affect learning performance in collaborative scaffolding condition?

Another important factor in learning is the relationship between cognition and motivation. It is often assumed that motivational factors mediate learning by increasing or decreasing cognitive engagement. Thus, motivation can be supposed as a mediating variable of cognitive load that can have constraints or stimulating functions on performance by improving learning. Another assumption is, the negative affection of collaboration by motivational features distracting learning activities by creating extraneous processing [21]. Given the relationship between extraneous load and learner engagement in the context of instructional design, it becomes necessary to look closer with a third research question: How does motivation conceptualised as learners' engagement affect extraneous load and performance?

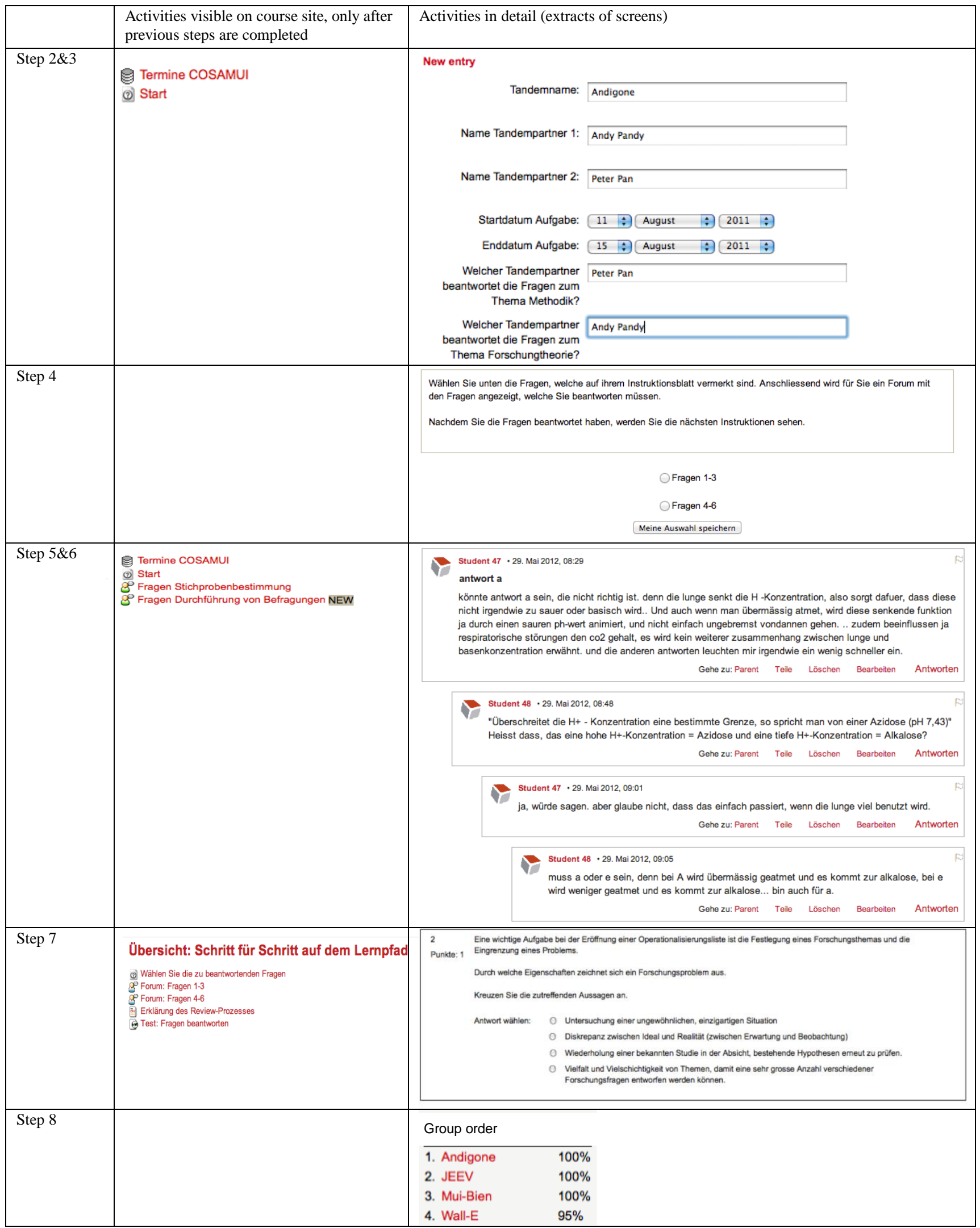

Fig. 1. Extracts of students' screens working through the exercise within collaborative scaffold (original course in German). 


\section{METHOD}

\section{A. Participants and Sampling}

41 psychology undergraduate students (33 female, 9 male, mean age $=24.10, \mathrm{SD}=1.93$ ) from a Swiss University participated in the investigation. They were remunerated with $40 \mathrm{CHF}$ for their participation.

\section{B. Learning Material and Assessment}

The MCQ were selected from an exercise course book and dealing with the topic of human blood circulation [22]. The learning assessment consisted of six questions for each testing condition. The questions were formulated as word problems with multiple-choice answers (A-Type: this means 4-5 possible answers, of which only one is correct). In order to prevent a systematic difficulty bias, the presentation of questions was balanced between the two experimental conditions. For each condition, the subjects had a maximum time of 60 minutes to solve the assignments.

\section{Measurements}

One option for measuring task difficulty is a rating to that effect [23]. Therefore a nine-point subjective symmetrical self-reporting scale for use in cognitive load measures [24] ranging from 1 (very, very low difficulty) to 9 (very, very high difficulty) was applied. Ratings were carried out after each problem during the assessments. For measuring mental effort, dual-task procedures are applicable. Brünken, Plass and Leutner classify this method as an objective measurement [23]. To measure effects, the subjects had to solve a primary task, consisting of the above-mentioned learning process steps 3 to 8 . In addition, they had to solve a secondary task (Dual Task Method) consisting of the presentation of letters in the lower left corner of the screen. Presented with two letters, the subjects had to decide which one comes first in the alphabet and push a corresponding button on the computer keyboard (F4 or F8). The dual task was refreshed at a rate of 30 seconds. As a variable for measuring mental effort we used errors that had occurred in the dual task assessment. We operationalized the third variable motivation by four items on a four-point Likert scales: 1) Compared to the individual assessment, was the collaborative assessment more motivating? 2) Did working with a partner motivate you? 3) Which learning activity motivated you more? 4) If you could choose, which manner of learning you would prefer for future learning activities? For these four items, a good reliability of Cronbach's $\alpha=0.80$ was achieved.

\section{Procedure}

The experiment was devised as a within-subjects balanced Latin square design $(2 \times 2)$ with the collaborative learning condition (scaffold) and an individual learning condition (classic MCQ). Learning-dyads were randomly formed in advance. After the reception, the subjects took their places in remote labs and were informed about the experiment procedures and trained in learning either individually or collaboratively on the platform. After the demographic data assessment, the participants started in either the collaborative or the individual condition by reading and learning the text and solving the MCQ-assessments.

\section{E. Data Analysis}

The data were analysed using the IBM SPSS Statistics Version 21 (Paired t-test, Pearson correlation, and ANCOVA). The ANCOVA was calculated with a General Linear Model (GLM) with a mean effect (dichotomized values) for mental effort measurements (dual task errors), and the covariates of task difficulty and motivation.

\section{RESULTS}

For the first step, we conducted a t-test to evaluate the performance of the learners within the two conditions. The performance was measured by allocating 1 point for every correct answer (min. 0, max 6). In the collaborative learning condition the mean of performance reached a higher score $M$ $=3.58(\mathrm{SD}=1.13)$ whereas in the individual learning condition $\mathrm{M}=2.45(\mathrm{SD}=1.45)$ with a statistically significant effect, $t$-value $=-4.27(p=.000)$.

In a second step, we performed correlation analysis (Pearson) of the collaborative learning condition with the cognitive load variables and motivation and performance. Only one significant correlation appeared (see Table I). Motivation correlates with performance $(r=0.41)$.

TABLE I: CORRELATIONS (R) OF THE VARIABLES

\begin{tabular}{|c|c|c|c|}
\hline $\begin{array}{l}\text { Collaborative } \\
\text { Learning }\end{array}$ & $\begin{array}{c}\text { Task } \\
\text { Difficulty }\end{array}$ & $\begin{array}{c}\text { Mental Effort } \\
\text { (Dual Task) }\end{array}$ & Motivation \\
\hline $\begin{array}{l}\text { Mental Effort } \\
\text {-Dual Task Errors }\end{array}$ & 0.10 & & \\
\hline $\begin{array}{cc} & \text {-Score } \\
\text { Performance } & \\
- \text { Score }\end{array}$ & $\begin{array}{l}-.022 \\
-0.04\end{array}$ & $\begin{array}{r}0.26 \\
-.018\end{array}$ & 0.41 \\
\hline
\end{tabular}

To investigate deeper, we calculated partial correlations of the cognitive load variables and performance. Firstly, we correlated mental effort with performance, controlling for task difficulty, resulting in a non-significant correlation $\mathrm{r}=$ -0.18. Secondly, we correlated mental effort with performance, controlling for task difficulty and motivation resulting in a significant correlation $r=-0.35(p=0.029)$. This second partial correlation indicatesa relationship between extraneous load (mental effort) and performance.

To consolidate this result, we conducted an ANCOVA with one factor (mental effort) and two covariates (task difficulty and motivation) by splitting the sample at the mean score of mental effort into two groups. In addition, we investigated the effect size by performing Cohen's d. Table II shows the means and standard deviations of performance by splitting the groups.

TABLE II: MEANS AND SD OF PERFORMANCE BY GOUP SPLITTING

\begin{tabular}{lccc}
$\begin{array}{l}\text { Group for Mental Effort (Dual } \\
\text { task errors) }\end{array}$ & $N$ & Mean & SD \\
\hline Low & 18 & 4.00 & 1.04 \\
High & 23 & 3.17 & 1.18 \\
\hline Total & 41 & & 1.11 \\
\hline \hline
\end{tabular}

This model was significant $(\mathrm{F}[3,37]=5.59 ; p=0.003)$ with an explained variance of $31 \%$ and showed a main effect between the two groups with an effect size of $d=0.73(F[1,39]$ 
$=6.86 ; p=0.013)$. Task difficulty showed no significant influence $F[1,39]=1.57(p=0.218)$ on mental effort. In contrast, motivation had a significant influence $F[1,39]=$ $13.73(p=0.001)$.

\section{DISCUSSION}

Looking at the data the following results stand out. Firstly, findings reveal that learners learning in pairs (collaborative condition) performed better than they did within the individual learning scenario. Secondly, performance in the collaborative condition (scaffold) is affected by mental effort, task difficulty, and motivation. The model explains about one third of the variance of the performance, and effect size is also considerable. Thirdly, mental effort measured by dual task errors performance is only affected by motivation but not by task difficulty. The results are in line with the CLT-research, which supposes that collaborative learning scenarios can lead to additional impacts affecting performance. As previously mentioned, collaborative scaffolding leads to additional cognitive load because subjects must perform mutual coordination. This leads to either a) to an additional extraneous load that requires additional mental effort or b) to an intrinsic load associated with a higher element interactivity causing higher task difficulty. Thus in collaborative learning arrangements, the relation between task difficulty and mental effort in the form of coordinative learning activities must be properly managed in order to avoid negatively affecting performance. Furthermore in our investigation, a positive correlation between motivation and learning performance ( $r=$ 0.45) occurred. Such a positive relation-ship between motivation and performance has also been found in other studies of cognitive load [25]. However, the data in Table 1 shows no significant correlations for task difficulty and mental effort. One possible explanation for this can be that in our investigation using a specific scaffold, extraneous load (measured by mental effort respectively dual task errors) affected performance in addition to motivation, whereas intrinsic load (measured by task difficulty) did not. Cierniak, Scheiter, and Gerjets' paper supports these findings, declaring that dual task measurement is an optimal instrument for predicting extraneous load differences [26]. In our view this points out the importance of managing extraneous load properly.

\section{CONCLUSIONS}

In pedagogical terms, this study exemplifies that scaffolding collaboration represents a way of supporting collaborative learning in pairs. We have applied three important principles in our study. First, enriching prior knowledge by executing an instruction and an exercise to learn about the working process in order to decrease additional coordination effort in collaboration. Second, defining a simple and explicit collaborative process to induce a favourable relation between invested mental effort and learning performance. Third, we used justification to stimulate learning collaborative learning activities.

Considering the role of motivation, we understand that motivation affects the collaborative learning performance.
However, it is important to differentiate between motivation and mental effort. Effort in CLT is conceptualised as an estimator of cognitive load. If the relationship between mental effort and task difficulty is inappropriate, cognitive overload arises and learning performance is hampered. In contrast, the motivation representing task involvement (to work collaboratively in our experiment) shows a positive relationship with performance. However, further investigations must determine accurately whether high motivation can lead in some groups to high effort investments towards either effective or perhaps also ineffective learning activities.

In our study, two other important aspects have not yet been addressed. The first point considers, which collaborative learning activities generate either additional mental effort or which increase or decrease task difficulty. The second concerns the impact of group size. Therefore, two further research directions arise.

First, future research should carve out more clearly than our study design, which collaboration processes generate additional mental effort either affecting intrinsic load in form of task difficulty or extraneous load in form of more transactional costs.

To do this, we need an approach that combines process-oriented with cognitive-load-oriented research [20]. However, we could determine no significant correlation between task difficulty and mental effort. Therefore we suppose a focus on inter-individual coordination and regulation while learning collaboratively would help to create fruitful instructional designs and foster our understanding of the relationship between task characteristic, task involvement, and learner- and group characteristics that affect performance. Second, we have developed a scaffold for learning in pairs that represents a simple collaborative constellation. If the number of group members increases, probably additional cognitive costs will give rise to other characteristics and processes and it would lead us to investigate whether task difficulty is also affected, and if task characteristics (e.g. justification sequences) need to be changed. Nevertheless, the findings of this study reveal that collaborative scaffolding is a promising method for stimulating effective collaborative learning.

\section{REFERENCES}

[1] M. J. Hannafin, S. M. Land, and K. Oliver, "Open learning environments: Foundations, methods and models," Instructional-Design Theories and Models: A New Paradigm of Instructional Theory," NJ: Lawrence Erlbaum Associates, 1999, vol. 2, pp. 115-140

[2] P. J. Beers, H. P. A Boshuizen, P. A. Kirschner, and W. H. Gijselaers, "The analysis of negotiation of common ground in CSCL," Learning and Instruction, vol. 17, no. 4, pp. 427-435, Aug. 2007

[3] C.-W. Tsai, "An online learning community integrated with web-enhanced collaborative learning and self-regulated learning," International Journal of Information and Communication Technology Education, vol. 7, no. 3, pp. 1-10, July 2011.

[4] P. Dillenbourg, "What do youmeanbycollaborativelearning?" Collaborative-Learning: CognitiveandComputationalApproaches, Oxford: Elsevier, 1999, pp. 1-19.

[5] F. Kirschner, F. Paas, and P. A. Kirschner, "Individual and group-based learning from complex cognitive tasks: Effects on retention and transfer efficiency," Computers in Human Behavior, vol. 25, no. 2, pp. 306-314, March 2009.

[6] D. Wood, J. S. Bruner, and G. Ross, "The role of tutoring in problem solving," Journal of Child Psychology and Psychiatry, vol. 17, no. 2, pp. 89-100, April 1976. 
[7] J. Pol, M. Volman, and J. Beishuizen, "Scaffolding in teacher-student interaction: A decade of research," Educational Psychology Review, vol. 22 no. 3, 271-296. April 2010.

[8] R. Azevedo, J. G. Cromley, and D. Seibert, "Does adaptive scaffolding facilitate students' ability to regulate their learning with hypermedia?" Contemporary Educational Psychology, vol. 29, no. 3, pp. 344-370, July 2004.

[9] H. L. Swanson and C. M. Lussier, "A selective synthesis of the experimental literature on dynamic assessment," Review of Educational Research, vol. 71, no. 2, pp. 321-63, Summer 2001.

[10] K. E. Chang, Y. T. Sung, and S. F. Chen, "Learning through computer-based concept mapping with scaffolding aid," Journal of Computer Assisted Learning, vol. 17, no 1, pp. 21-33, March 2001.

[11] M. C. Kim and M. J. Hannafin, "Scaffolding problem solving in technology-enhanced learning environments (TELEs): Bridging research and theory with practice," Computers \& Education, vol. 56, no. 2, pp. 403-417, Feb. 2011.

[12] I. Molenaar, C. Roda, C. Boxtel, and P. Sleegers, "Dynamic scaffolding of socially regulated learning in a computer-based learning environment," Computers \& Education, vol. 59, no. 2, pp. 515-523, Sep. 2012.

[13] K. E. Chang, Y. T. Sung, and S. F. Chen, "Learning through computer-based concept mapping with scaffolding aid," Journal of Computer Assisted Learning, vol. 17, no. 1, pp. 21-33, March 2001.

[14] N.-S. Chen, D. C.-E. Teng, C.-H. Lee, and Kinshuk, "Augmenting paper-based reading activity with direct access to digital materials and scaffolded questioning," Computers \& Education, vol. 57, no. 2, pp. 1705-1715, Sep. 2011

[15] K. Topping, "Peer assessment between students in colleges and universities," Review of Educational Research, vol. 68, no 3, pp. 249-276, Fall 1998.

[16] S. W. Draper, "Catalytic assessment: understanding how MCQs and EVS can foster deep learning," British Journal of Educational Technology, vol. 40, no. 2, pp. 285-293, March 2009.

[17] T.-H. Wang, "Developing Web-based assessment strategies for facilitating junior high school students to perform self-regulated learning in an e-Learning environment," Computers \& Education, vol. 57, no. 2, pp. 1801-1812, Sep. 2011.

[18] A. D. Baddley, Working Memory, Oxford: Clarendon Press, 1986

[19] J. Sweller, "Element interactivity and intrinsic, extraneous, and germane cognitive load," Educational Psychology Review, vol. 22, no. 2, pp. 123-138, June2010.

[20] J. Janssen, F. Kirschner, G. Erkens, P. A. Kirschner, and F. Paas, "Making the black box of collaborative learning transparent: Combining process-oriented and cognitive load approaches" Educational Psychology Review, vol. 22, no. 2, pp. 139-154, June 2010.

[21] R. E. Mayer, "Incorporating motivation into multimedia learning," Learning and Instruction, vol. 29, pp. 171-173, Feb. 2014.

[22] R. Goertz,H. G. Schlamelcher, L. Schiffmann, R. Pretzschel, J. Glaubitz, and U. Schröter, "Taste the Test," 2nd ed., vol. 2, Cologne: Medtestverlag, 2007

[23] R. Brünken, J. L. Plass, and D. Leutner, "Direct measurement of cognitive load in multimedia learning," Educational Psychologist, vol. 38, no. 1, pp. 53-61, 2003

[24] F. Paas, J. J. G. Merriënboer, and J. J. Adam, "Measurement of cognitive load in instructional research," Perceptual and Motor Skills, vol. 79, no. 1, pp. 419-430, Aug. 1994.
[25] W. Schnotz, "Reanalyzing the expertise reversal effect," Instructional Science, vol. 38, no 3, pp. 315-323, May 2010.

[26] G. Cierniak, K. Scheiter, and P. Gerjets, "Explaining the split-attention effect: Is the reduction of extraneous cognitive load accompanied by an increase in germane cognitive load?" Computers in Human Behavior, vol. 25, no. 2, pp. 315-324, March 2009.

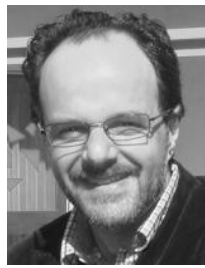

Per Bergamin studied general, applied psychology and education at University of Fribourg, Switzerland. He is a professor for didactics in distance education and e-learning at the Swiss Distance University of Applied Sciences (FFHS). In this function he is the co-director of the Institute for Research in Open, Distance and e-Learning (IFeL) where his main research issues are self-regulated, adaptive and mobile learning as well as e-reading and usability.

As a researcher he cooperates with or leads different national and international projects. He is one member of the Technology Working Group of e-Learning Support Centers of the Swiss universities and Advisory Board for e-Learning Development of the Swiss Universities of Applies Sciences and of Swiss Foundation for audio-visuel education. As a teacher he covers the topics of educational psychology and E-Didactics. Furthermore Per Bergamin is the founder of an international company for e-business and learning-applications, where he acts today as the president of the executive board.

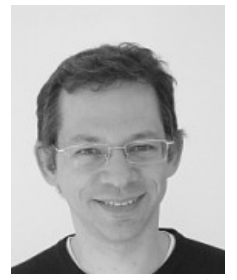

Egon Werlen studied clinical psychology, experimental psychology and communication sciences at the University of Fribourg with a doctoral degree in psychology $(\mathrm{PhD})$.

Since 2011, he is a scientific collaborator at the Swiss Distance University of Applied Sciences (FFHS) in brig. He works at the Institute for Research in Open, Distance and e-Learning (IFeL). His main research domains are self-regulated learning as well as emotional reactions and cognitive load in e-learning and e-reading. He got a specialization as health psychologist FSP. For several years he did research in this field, still a domain of interest, together with digital media literacy. He is one member of the editorial board of the Open Journal of Medical Psychology. At the FFHS, he's teaching in a blended learning course the "basics of health psychology."

Dr. Werlen is member in several professional societies. Actually, he is the president of the Association of Psychologists of Valais (APVs), which is a part of the Federation of Swiss Psychologists (FSP), one member of the executive board of the Swiss Health Psychology Society (SHPS), one member of the Swiss Psychology Society (SGP) and the European Health Psychology Society (EHPS).

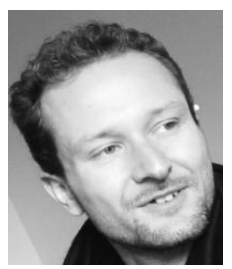

Yves Bochud was born in 1984 in Bern, Switzerland. After completion of the master program in psychology at the University of Bern in 2010, he is now writing his doctoral thesis on e-reading research at the Institute of Psychology, Section for Cognitive Psychology, Perception and Research Methods, University of Berne, Switzerland. Currently, he works as a scientific collaborator and data specialist for the Federal Office of Public Health in Bern, Switzerland. His main research interests lie in the domain of e-reading, usability and the application of new media in education as well as their influence on learning and understanding. 